\title{
PEDAGOGICAL CONDITIONS FOR THE FORMATION OF LEADERSHIP QUALITIES OF FUTURE HEADS OF PRESCHOOL EDUCATION INSTITUTIONS
}

\author{
Yuliya Volynets, \\ Borys Grinchenko Kyiv University, \\ Candidate of Pedagogical Sciences, \\ Senior lecturer of Preschool education department, \\ Preschool Education Department of Pedagogical Institute, \\ Kyiv, Ukraine \\ https://orcid.org/0000-0002-3849-0821 \\ y.volynets@kubg.edu.ua \\ Nadiia Stadnik, \\ Municipal Institution of Kyiv Regional Council \\ «Bila Tserkva professional humanitarian and pedagogical College», \\ Candidate of Pedagogical Sciences, Senior lecturer of the Department of \\ Pedagogy and Psychology of Preschool and Primary Education, \\ Bila Tserkva, Ukraine \\ https://orcid.org/0000-0002-2619-4419 \\ n.stadnik72@ukr.net \\ Tetiana Panchenko, \\ Municipal Institution of Kyiv Regional Council \\ «Bila Tserkva professional humanitarian and pedagogical College», \\ Candidate of Ppsychological Sciences, Senior lecturer of the Department of \\ Pedagogy and Psychology of Preschool and Primary Education, \\ Bila Tserkva, Ukraine \\ https://orcid.org/0000-0002-5010-652X \\ panchtanya@ukr.net
}

\begin{abstract}
The urgency of the studied problem is because in conditions of significant socio-economic changes, the system of human resource management technologies becomes significant, especially relevant is the use of the potential of leadership influence. In this regard, this article is aimed at revealing the problem of developing leadership qualities of heads of preschool education institutions. The article highlights current issues of leadership development of future heads of preschool education. The leading method of the research of this problem is the analysis of the researched problem in pedagogical theory and practice and experimental check of pedagogical conditions of formation of leadership qualities of future heads of preschool educational institutions that allows to reveal and characterize features of formation of leading qualities of future heads of preschool educational institutions. The article identifies the components, criteria, indicators and describes the levels of leadership development of future leaders of preschool education. The basic
\end{abstract}


concepts of the problem are defined: leader, leadership, professional qualities of the leader, leadership qualities of future heads of preschool educational institutions, pedagogical conditions of formation of leadership qualities of future heads of preschool educational institutions. Relevant requirements to the personal and professional qualities of a leader are revealed. The structural components of leadership qualities of future heads of preschool education institutions are characterized, namely: motivational-value, integrative-activity, directional-activity, emotional-reflexive. The pedagogical conditions of the formation of leadership qualities of future heads of preschool education institutions are substantiated. The offered materials of the article represent practical value for heads of preschool education institutions, educators-methodologists, and future teachers of preschool education.

Keywords: leadership, leadership qualities, manager, pedagogical conditions of formation of leadership qualities of future heads of preschool education institutions.

\section{INTRODUCTION}

In the context of significant socio-economic changes, the system of human resource management technologies is becoming essential, especially the use of the potential of leadership influence. Since leadership is the highest form of professional leadership skills, to acquire professional competence, the head of a preschool institution must have developed leadership qualities. That is why specialists in administrative management need the development of leadership skills while studying in a higher education institution to further their development in professional activities. Leadership combines the processes of domination, subordination, influence, direction, consistency in the system of interpersonal relations in the group, ensuring the achievement of a group of specialists a certain goal and quality results. Important for our study is the conclusion formulated by N. Yakushko that «leadership is considered as a new management paradigm, the essence of which corresponds to modern realities and trends in society. The introduction of leadership principles in the system of professional training of future managers of preschool educational establishment should be based on the development of leadership potential of managers, which requires modernization of the defining parameters of the system of professional training of managers» (N. Yakushko, 2018).

\section{MATERIALS AND METHODS}

The following methods were used in the research process: theoretical: theoretical analysis of pedagogical literature; comparative analysis of facts, documents, views; empirical: pedagogical experiment (ascertaining, formative), diagnostic (questionnaire, conversation, testing, comparison, expert assessment); observational: (pedagogical observation, self-analysis), analysis of the obtained results.

The article presents the pedagogical conditions for the formation of leadership qualities of future heads of preschool education, which form the theoretical basis of the study are (systematic, personality-oriented, activity, dialogical, and competence approaches to the 
professional training of future heads of preschool education; provisions on the impossibility of cognition without motivation activities, the unity of consciousness and activity, the role of practice in the process of learning and the relationship of real-life and its cognitive activity, the concept of continuing education, personality-oriented approach to the educational process, theoretical foundations of the educational process in higher education, theoretical and practical provisions for professional activities and training of future heads of preschool education institutions; psychological and pedagogical foundations of the leadership development process).

The leading method of the research of this problem is the method of modeling, which allows considering this problem as a purposeful and organized process of improving professional, cultural, and managerial competencies of specialists in preschool education, they need for effective educational activities in preschool education.

\section{RESULTS AND DISCUSSION}

Leadership as a social phenomenon is studied in the activities of a certain group of people, including a small group. We agree with the researcher B. Goloveshko, who formulates the conclusion that the leader in a small group should direct informal interpersonal communication (B. Goloveshko, 2017), which is important for determining the leadership qualities of future heads of preschool education, one of the main tasks of which is to ensure the maintenance of coordinated teamwork. Based on the results of scientific research of V. Kremen, B. Goloveshko, the concept of «leader» is defined as the ability of the head of preschool education to play a central role in organizing joint activities and regulating relationships in the team, which delegates the right to make decisions in important situations; leads the team in achieving a certain goal, integrates and directs its activities (B. Goloveshko, 2017).

The scientist E. Ilyin defines the following features of a leader: he belongs to a group in which he occupies an influential and authoritative position; by his personal actions contributes to the achievement of goals and interests of the group; takes the initiative and responsibility; affects all members of the group who implement its decisions (E. Ilyin, 2000). According to J. Maxwell, «the leader is a person who knows the way, follows this path and shows it to others» (B. Goloveshko, 2017). This statement emphasizes the main characteristics of a leader, which are determined by scientists. Defining leadership as «position, personality and the process of involving followers in certain activities», researcher S. Kalashnikov notes that «the primary basis of leadership is the personality of the leader, his leadership qualities» (S. Kalashnikov, 2010).

Relevant for our study is the definition of the essence of the concept of «leadership qualities», proposed by A. Pilganchuk and V. Kuzmenko, who understand it as «personality qualities that provide effective leadership, individual and socio-psychological personality traits that affect the group and ensure the achievement of the goal (B. Goloveshko, 2017 and A. Pilhanchuk, V. Kuzmenko, 2012).

Formulating the goals of the article - theoretical substantiation and experimental verification of pedagogical conditions of formation of leadership qualities of future heads of preschool educational institutions. 
The experimental work was performed based on Kyiv University named after Borys Hrinchenko, Municipal Educational Institution of the Kyiv Regional Council «Kyiv Regional Institute of Postgraduate Education of Teachers».

Based on a study of the scientific literature on the nature of leadership, it has been found that leaders have the following qualities: a leader's lifestyle involves a combination of career and personal life; the leader does not stop in his development; the vocation of a leader is manifested in the use of abilities and acquired knowledge, skills, talent as a way of selfrealization in interaction with other people (N. Yakushko, 2018). A leader as a charismatic personality is characterized by the following personal qualities and skills: high level of mental abilities, broad public interests, maturity (N. Yakushko, 2018); organization, confidence in their actions and decisions, sense of dignity, energy, adequacy, balance, emotional and stress resistance, the ability to act quickly and thoughtfully in different situations and manage them, to succeed, to inspire others by their own example; has developed rhetorical abilities (can express his own opinion, convincing, has the skills of interpersonal communication); objectively assesses his abilities; ability to take care of one's appearance, mastery of pedagogical techniques (B. Goloveshko, 2017).

Based on the study of leadership concepts 0. Morgulets identified the following main approaches to leadership: an approach based on leadership qualities (the first, traditional approach, which assumes the presence of unique personality traits that he receives from birth, a high level of intelligence and education, expressive appearance, self-confidence, initiative, etc.; is the basis of other concepts); behavioral approach (assumes that leadership qualities can be successfully developed, not necessarily born a leader); situational approach (determines that the effectiveness of leadership directly depends on the specific situation, but the personal qualities and behavior of the leader are also important factors of leadership) (B. Goloveshko, 2017 and O. Morgulets, 2012).

Thus, the analysis of leadership qualities of the individual is based on the study of stable character traits of the individual, it is believed that the leader has certain innate traits that ensure the effectiveness of his activities. The basis of the behavioral approach is the classification of leadership styles and behavior, observation, and analysis of images of leadership behavior that are manifested in the specific actions of leaders. Determinant in the behavioral approach is the style of behavior of the leader with subordinates. The dynamics of behavior reflects what is the criterion for analyzing the activities of the leader: «statics, which involves the analysis of leadership qualities of the individual, or the dynamics based on the analysis of the leader's behavior» (N. Yakushko, 2018). The research results confirm the inexpediency of the advantage of a particular leadership style, confirm the need for flexible application of different leadership styles in specific situations (N. Yakushko, 2018).

In the context of the formation of leadership qualities in future heads of preschool education institutions, while studying in a higher education institution, it is necessary to consider the essence of the concept of "professional qualities of a leader». Scientists define the following basic provisions of the concept of «professional qualities»: «individual properties of the subject of activity, which are necessary and sufficient for its implementation at the normative level and which significantly and positively correlate with at least one or more of its main performance parameters - quality, productivity, reliability» (A. Karpov, 2003); 
«Personality qualities that determine productivity, quality, performance» (E. Zeyer, 2003); «Individual qualities of the subject of activity, influencing the efficiency of activity and the success of its development» (V. Shadrikov, 1982); «A set of professional qualities that serve the successful implementation of professional activities, effective solution of professional tasks, personal and professional growth and improvement» (M. Akhmetova, 2004 and B. Goloveshko, 2017).

Researchers M. Klishchevska and G. Solntseva in the context of defining professionally important qualities use the concept of «individual and personal characteristics», in particular - the necessary and sufficient qualities. The necessary qualities are manifested in such features of the leader, which allow to describe it in all its variety of manifestations, determine the effectiveness of the leader; sufficient qualities distinguish it from others (B. Goloveshko, 2017 and M. Klishchevskaya, G. Solntseva, 1999).

Z. Gaponyuk identifies the following groups of potential qualities of a leader: generalprofessional, creative, socio-psychological, social-communicative (Z. Gaponyuk, 2008). The general professional qualities include theoretical knowledge, practical experience, systematization of professional issues, ability to adapt to the situation, ability to prognostic activities, quality performance of professional duties, responsibility, ability to manage the team, highlight the main and secondary, properly manage their own sometimes and distribute responsibilities in the team. Creative qualities combine creativity, initiative, openness to change, integrativeness; ability to develop and implement innovative educational projects and programs, to train preschool education specialists for innovative educational activities, to use research activities in the management of the educational process, and methodological work. Socio-psychological qualities combine: creating a comfortable, safe, developmental, inclusive educational environment; humanism, flexibility, tolerance, positive thinking, the ability to be an example to follow, establish interpersonal contacts, have confidence and commitment to themselves, understand people, and influence their activities and behavior, implement an individual approach to each specialist, determine the optimal pace of work, justify their own opinion, persuade, form a positive attitude to the activities and behavior of the leader; emotional and stress resistance, the tendency to analysis and introspection, application of reflective practices. Socio-communicative qualities include the ability to communicate and establish professional contacts, assertiveness (the ability to defend their own opinions, justify their own opinions, show respect for the interests of the whole team and individuals, their personal space), to manage communication between team members, the ability to use channels and mechanisms of communication, technologies of communicative activity.

In the context of combining an approach based on leadership qualities of personality, behavioral and situational approaches, it is important to determine the components of the structure of leadership qualities proposed by V. Lokshin: general personal qualities of a leader that form his value system, attitude to people and the world; leader behavior that involves mutual understanding, perception, evaluation, etc.; a situation that determines the success of the leader (V. Lokshin, 2013).

The results of the research confirm the importance of the following leadership qualities of personality: sociability, activity, initiative, persistence, self-control, ability to work, 
observation, organization, independence, persuasiveness, determination, erudition, selfconfidence, emotional attractiveness, ability to persuade Goloveshko, 2017 and A. Zorina, 2009); intelligence, sociability, empathy, kindness (B. Goloveshko, 2017 and T. Vezhevych, 2001).

B. Goloveshko notes that «leadership qualities needed by a specialist to achieve a leadership position in specific conditions, the implementation of effective leadership influence and the realization of leadership potential, play a role in the activities of the leader» (B. Goloveshko, 2017). Analyzing the specifics of professional activity, we can identify qualities that should take into account the following factors in the formation of leadership qualities of future leaders of Preschool educational institution (next PEI): social and educational challenges; features of the social and educational environment; the purpose and objectives of management, professional roles performed by the leader, etc.

Based on the analysis of the scientific literature, we have identified the essence of the concept of «leadership qualities», which we understand as a combination of individual and socio-psychological personality traits that ensure the achievement of management goals in a particular situation, effective leadership, and leadership potential.

Researchers V. Stadnyk and M. Jochna note that «for the successful work of the team it is important not only the relationships formed in it but also how their activities are directed, what forms of influence are used to encourage people to work productively. These issues belong to the competence of the leader who leads the team and uses power to influence people's behavior (B. Goloveshko, 2017 and V. Stadnyk, M. Jochna, 2003). Giving the head formal power is insufficient to perform leadership functions, which necessitates the formation of leadership qualities of the future head of the preschool institution to achieve the goals of management and educational activities.

Researchers G. Hernes-Broome, R. Hughes noted that the approach that involves the formation of leadership qualities will remain relevant in the future, however, changing the set of such qualities will be accompanied by the transformation of the competitive environment, the factors of which are «global competition, information and communication, and digital technologies, the growing role of teams in achieving professional goals, the need to meet the needs of society, community, subjects of the educational process in the efficiency, flexibility, mobility, predictability of organizations» (B. Goloveshko, 2017 and G. Hernez-Broome, R Hughes L., 2004).

Important for our study is the analysis of the multifunctional concept of «management», which is considered by scientists as one that is used mainly to characterize the management processes of business organizations (enterprises). «Management» is an extremely broad and multidimensional concept. Etymologically, management comes from the Latin word «manus» - hand. Initially, this word meant the ability to carefully manage the household, skillfully own the means of labor, work skillfully. With the advent of many types of work, with the deepening of specialization, there was a need for activities that integrated the work of many individual performers. Accordingly, the meaning of the concept of «management» was transformed. This word has absorbed all the numerous requirements for management as a science, art of business, and style of work (Z. Pushkar, B. Pushkar, 2017).

Given the functional responsibilities of the head, appropriate requirements are formed for his 
personal and professional qualities. The head must have a set of knowledge, skills, and abilities to manage an educational institution or its structural unit, have a willingness to manage, critical thinking, experience, values, which will ensure the quality and efficiency of his professional activity.

Using the provisions of the competency approach, T. Batalova defines the following functional roles of a modern leader: «the ability to be a manager-leader, to intensify the activities of followers; ability to manage the team; the ability to be an example to follow, to influence people to achieve certain goals; ability to use modern methods and technologies in the process of managing an educational institution, including information and communication; ability to work in a team, ability to work effectively as a team member, its leader; ability to be a strategist», to transform their activities and the activities of preschool education; ability to innovative and creative thinking, the realization of creative potential in professional activity, management of innovative educational activity; ability to distinguish opinions and arguments, evaluate them, establish cause-and-effect relationships; ability to continuous professional development (B. Goloveshko, 2017 and T. Batalova, 2004).

Thus, the combination of the above positions involves the formation of a set of personal qualities of the head of the educational institution, which are the basis for the implementation of his leadership in professional activities, managerial influence on participants in the educational process.

In the process of developing curricula, it is important to analyze the current state of management of preschool education and forecast future challenges (O. Romanovsky, O. Ponomarev, O. Ignatiuk, etc., 2011).

The synergetic paradigm of higher school pedagogy presupposes that in numerous bifurcation points the student should be influenced to direct the process of professional training, formation of leadership qualities of personality, the realization of the individual trajectory of professional and personal development of future heads of preschool education institutions. In the context of the synergetic paradigm, higher education institutions involve practitioners in the educational process, the participation of future leaders of PEI in the preparation and implementation of methodological activities, the work of professional associations of PEI leaders (workshops, pedagogical studies, workshops, round tables). training, etc). The involvement of future leaders of PEI in the preparation and conduct of such activities will contribute to the formation of their leadership qualities.

Let's define and characterize the structural components of leadership qualities of future leaders of PEI, namely: motivational-value, integrative-activity, directional-activity, emotional-reflexive. In the process of scientific research, we used the provisions of a study conducted by B. Goloveshko (B. Goloveshko, 2017) on the structural components of leadership qualities of future leaders and their content.

Motivational and value component of leadership qualities of the future head of PEI combines the focus on new achievements and goals, the formation of the level of claims and values to the management of the leader, flexibility, positivity, and constructiveness of professional thinking; openness to change, innovation; the need for self-realization in professional activities, the focus on recognition, the desire to increase education and professional development and self-improvement. The integrative-activity component of 
leadership qualities of the future head of PEI combines initiative, energy; ability to attract, activate, organize and unite the team; systematic management; communicative competence. The directional and activity component of the leadership qualities of the future head of PEI is manifested in the ability to model the educational environment, the activities of the team, the professional development of staff, the expected results of educational activities. The emotional-reflexive component of leadership qualities of the future head of PEI is manifested in emotional and ethical competence, which combines the ability to understand their own emotions and their causes, the impact of a particular emotion on human behavior; attention to the manifestation of emotions of others; ability to objectively interpret the external manifestation of emotions; ability to activate, maintain or deactivate their own emotions; ability to activate a certain emotion, reduce the intensity of unwanted emotion of another person (B. Goloveshko, 2017).

Thus, the motivational and value component of leadership qualities of the future head of PEI characterizes a set of motives and values that determine the success and effectiveness of management activities of the leader of the educational institution; integrative-activity component of leadership qualities of the future head of PEI is characterized by a set of organizational and communicative abilities that provide the ability of the future head of PEI to integrate the activities of the group as a single team; the directional-activity component of leadership qualities of the future head of PEI is characterized by a complex of abilities on decision-making and establishment of the purposes providing purposeful educational activity, professional development of collective; emotional-reflexive component of leadership qualities of the future head of PEI is characterized by a set of abilities to recognize and manage their own emotions and the emotions of others, providing his emotional stability and stress resistance, the ability to express itself as a standard.

The study found that the general basis for the formation and development of the manager as a specialist, a competent leader is his intellectual qualities, which determine the success, quality, and effectiveness of his management in influencing the team to achieve certain goals and objectives. Solving the problem of forming the leadership qualities of future heads of preschool education institutions required clarification of the criteria, indicators, and levels of formation of leadership qualities of future leaders of preschool education. In our study, we proceed from the fact that the definition of criteria and indicators, levels of leadership qualities of future leaders of PEI combines the following structural components: motivational-value, integrative-activity, directional-activity, emotional-reflexive.

We have identified the criteria and indicators of the formation of leadership qualities of future leaders of PEI, presented in the study of B. Goloveshko, according to the above components (B. Goloveshko, 2017). Motivational and value component of leadership qualities of the future head of PEI characterizes a set of important motives and values that determine the success and effectiveness of the head of PEI as a leader of the organization's staff. The following indicators of motivational and value criterion of formation of leadership qualities of future leaders of PEI are determined: the need to achieve the goal, motivation to succeed, professional orientation (B. Goloveshko, 2017). The integrative-activity component of the leadership qualities of the future head of the PEI characterizes a set of organizational and communicative abilities that provide the ability of the future head of the PEI to integrate 
the activities of the group as a single team. Organizational and communicative abilities are determined by indicators of integrative-activity criterion (B. Goloveshko, 2017). The directional and activity component of the leadership qualities of the future head of the PEI is characterized by a set of decision-making and goal-setting abilities that ensure the purposefulness of the team as a whole. Indicators of goal-setting criterion determine the ability to set goals, plan, and make decisions (B. Goloveshko, 2017). The emotional-reflexive component of leadership qualities of the future head of PEI is characterized by a set of abilities to recognize and manage their own emotions, the ability to influence the emotions of others, the ability to show themselves as an example to follow. Indicators of emotionalreflexive criterion determine the ability to understand their own and others' emotions, manage their own emotions, to influence the emotions of others (B. Goloveshko, 2017).

The ascertaining stage of the research was carried out with the 5th year students of the specialty 012 «Preschool education» of the second (master's) level of higher education of the Pedagogical Institute of Kyiv University named after Borys Hrinchenko. The purpose of the ascertaining stage of the experiment was to determine the level of formation of leadership qualities of future leaders of PEI. Following the defined components, criteria, and indicators, we distinguish the following levels of formation of leadership qualities of future leaders of PEI: high, sufficient, initial. We characterize the levels of formation of leadership qualities of future leaders of PEI in accordance with certain criteria and indicators. Indicators of the motivational-value criterion are the need to achieve the goal, motivation to succeed, professional orientation. The high level of need to achieve the goal implies the desire for new achievements, a high degree of persistence in achieving goals, the presence of a developed spirit of rivalry and aspirations, the manifestation of positive emotions in the process of achieving the goal. A sufficient level of need to achieve the goal is manifested in the desire for new achievements, a sufficient degree of persistence in achieving goals, the desire to do the job well, the process of achieving the goal does not cause special emotions. The initial level of need to achieve the goal involves a sense of satisfaction with the achieved or lack of reasoning about it, the initial degree of persistence in achieving goals, lack of spirit of rivalry, the manifestation of negative emotions about actions aimed at achieving the goal.

A high level of motivation to succeed implies the need for self-realization in the process of professional activity, a clear focus on recognition in the public environment, the presence of a clearly articulated positive result. A sufficient level of motivation to succeed is manifested in the need for self-realization in the process of professional activity, a sufficient degree of focus on recognition in the social environment, an abstract idea of achieving a positive result. The initial level of motivation to succeed implies the initial degree of need for selfrealization in the process of professional activity, there is no focus on recognition in the public environment, focus on finding ways to solve or avoid problematic/negative situations in management.

A high level of professional orientation implies the presence of a high degree of significance of the professional activity, the desire to increase the level of education and professional skills, awareness of the future head of PEI leadership as a type of management interaction between leaders and followers. A sufficient level of professional orientation indicates the presence of high significance for the person of his professional activity or the desire to increase the 
level of education and professional skills, leadership is considered outside the professional competence of the future head of PEI. At the initial level, the importance of professional activity, the desire to increase the level of education, understanding the essence of the concept of «leadership», its role in the management of the future head of PEI is not traced.

Organizational and communicative abilities are determined by the indicators of integrativeactivity criterion.

The high level of organizational skills presupposes initiative and social activity, the ability to attract and activate members of the team as the future head of the PEI, a systematic approach to the analysis of their work and educational activities of the educational institution. A sufficient level of organizational skills is manifested in a sufficient degree of initiative and social activity, fragmentary ability to attract and activate team members, systematic analysis of the work of the future head of PEI, and educational activities of the educational institution. The initial level of organizational skills involves the initial degree of initiative and social activity, there is no trace of the ability to attract and activate team members, there is chaos in the analysis of work.

Indicators of goal-setting criterion determine the ability to set goals, plan, make decisions. A high level of goal-setting abilities implies a high degree of ability to define goals and present the modeled phenomenon, its structure, forecasting options for solving problems. A sufficient level of goal-setting abilities indicates a sufficient degree of ability to define goals and present the modeled phenomenon, its structure, forecasting options for solving problems. The initial level of goal-setting abilities presupposes the initial degree of ability to define goals and present the modeled phenomenon, its structure, forecasting options for solving problems.

A high level of planning skills implies a conscious tendency to plan management and educational activities, a high degree of ability to achieve goals, planning is characterized by realism and hierarchy. A sufficient level of planning skills implies readiness to plan managerial and educational activities, a sufficient degree of ability to achieve the goal, realistic and hierarchical planning can be traced. The initial level of planning skills is manifested in the immaturity of skills to plan management and educational activities, the activity is characterized by situationality and inconsistency.

A high level of decision-making skills requires determination and balance in their decisionmaking, change of decisions (if necessary), adequacy of assessment of the consequences of decisions, objective and impartial attitude to the results of management. A sufficient level of decision-making skills is characterized by the formation of readiness to make decisions, prudence, and at the same time - impulsiveness in decision-making, lack of flexibility in their adjustment, a sufficient degree of adequacy to assess the consequences of decisions, errors. The initial level of decision-making skills is characterized by fluctuations and impulsiveness in decision-making, decisions remain unchanged or canceled, the initial degree of adequacy of evaluation of the results of decisions, errors are not taken into account.

Indicators of the emotional-reflexive component determine the ability to understand their own and others' emotions, control their own emotions, the impact on the emotions of others.

A high level of understanding of one's own emotions presupposes a high degree of awareness of one's own emotions and their causes, the influence of a particular emotion 
on the behavior of the future head of PEI. A sufficient level of understanding of one's own emotions presupposes a sufficient degree of awareness of one's own emotions and their causes, the influence of a particular emotion on the behavior of the future head of PEI. The initial level of understanding of one's own emotions indicates the initial degree of attention to one's own emotions, the causes of emotions are mostly not interpreted, the influence of a particular emotion on the behavior of the future head of PEI is not realized.

A high level of understanding of other people's emotions implies a high degree of attention, sensitivity, tact to the emotions of others, the ability to objectively interpret the external manifestation of emotions, accompanied by a manifestation of communicative activity to understand other people's emotions. A sufficient level of understanding of other people's emotions implies a sufficient degree of attention, sensitivity, tact to the emotions of others, the ability to objectively interpret the external manifestation of emotions, accompanied by a manifestation of communicative activity to understand other people's emotions. The initial level of understanding of other people's emotions indicates that the emotions of others are fixed chaotically, the interpretation of the external manifestation of emotions is superficial.

A high level of management of one's own emotions implies the ability to control the external manifestation of one's own emotions, a high degree of ability to activate, maintain or deactivate one's own emotions. A sufficient level of management of one's own emotions is manifested in the ability to control the external manifestation of one's own emotions, a sufficient degree of ability to activate, maintain or deactivate one's own emotions. The initial level of control of one's own emotions is manifested in the initial stage of control of the external manifestation of one's own emotion, the ability to activate, maintain or deactivate one's own emotion.

A high level of influence on the emotions of others implies a high ability to activate the necessary emotions of another person and a high degree of ability to reduce the intensity of unwanted emotions of another person. A sufficient level of influence on the emotions of others implies a sufficient degree of activation of the necessary emotion of another person, reducing the intensity of his unwanted emotions. The initial level of influence on the emotions of others is manifested in the low ability to activate the necessary emotions of another person, reducing the intensity of his unwanted emotions.

Thus, the defined criteria, indicators, and levels of formation of leadership qualities of future leaders of PEI are the basis for the ascertaining stage of the experiment, which involves the use of a set of diagnostic techniques; further substantiation of pedagogical conditions on the research problem, which are presented in the following paragraphs.

Thus, the defined criteria, indicators and levels of formation of leadership qualities of future leaders of PEI are the basis for the ascertaining stage of the experiment, which involves the use of a set of diagnostic techniques; further substantiation of pedagogical conditions on the problem of research, which are presented in the following paragraphs.

Determining the criteria, indicators, and levels of leadership qualities of the respondents involved the use of the following research methods: interview, observation, testing.

The experimental study involved 56 respondents: 23 students of the experimental group (EG) and 23 leaders of PEI control group (CG). In the process of the ascertaining stage of the experiment the comparison of the formation of leadership qualities of future leaders of PEI 
(students of V course of specialty 012 «Preschool education» of the second (master's) level of higher education) and leaders of PEI who studied at advanced training courses in the specialty «Directors of preschool education institutions» was made. To determine the level of formation of leadership qualities, a set of diagnostic methods was used: the method «Need to achieve the goal» (Yu. Orlov) (O. Yeliseyev, 2003), «Methods for diagnosing motivation to succeed» (T. Ehlers) (V. Rozanova, 1999 ), «Questionnaire of terminal values (OTeC)» (I. Senin, 1991), the method of «Communicative and organizational tendencies (KOS-2)» (V. Sinyavsky, B. Fedorishin, and N. Fetiskin, 2002), the method of «Self-regulation style» behavior» (V. Morosanova, 1995), test for emotional intelligence «Emin» (D. Lusin, 2006).

The ascertaining stage of the pedagogical experiment involved assessing the level of formation of respondents' leadership qualities according to certain components. The level of formation of the motivational-value component was determined by the level of manifestation of the need to achieve the goal, motivation to succeed, and the definition of the hierarchy of the dominant sphere of life. To determine the level of manifestation of the need to achieve the goal, the method of «Need to achieve the goal» was used by Yu. Orlov. Determination of motivation to succeed was carried out using the «Methods of diagnosing motivation to succeed» by T. Ehlers. Psychodiagnostics of the hierarchy of the dominant sphere of life was carried out by ranking and further analysis of the products of activity (among the working managers of PEI - conversation) and the use of «Questionnaire of terminal values (OTEC)» by I. Senin.

Among the respondents, at the beginning of the study, there was a survey. So, for example, to the question «What motives motivate you to a managerial position in PEI?» we determined that professional - 44 respondents $(78,6 \%)$; cognitive - 41 respondents $(73,2 \%)$; moral -31 respondents (55,4\%); material -8 respondents $(14,3 \%)$; the rest 4 respondents $(7,1 \%)$. To the question «Would you be able to self-realize in the profession through management?» answered: «yes» - 35 people $(62,5 \%)$; «no» - 16 people $(28,6 \%)$; «didn't think about it - 5 (8,9 \%) (fig. 1).

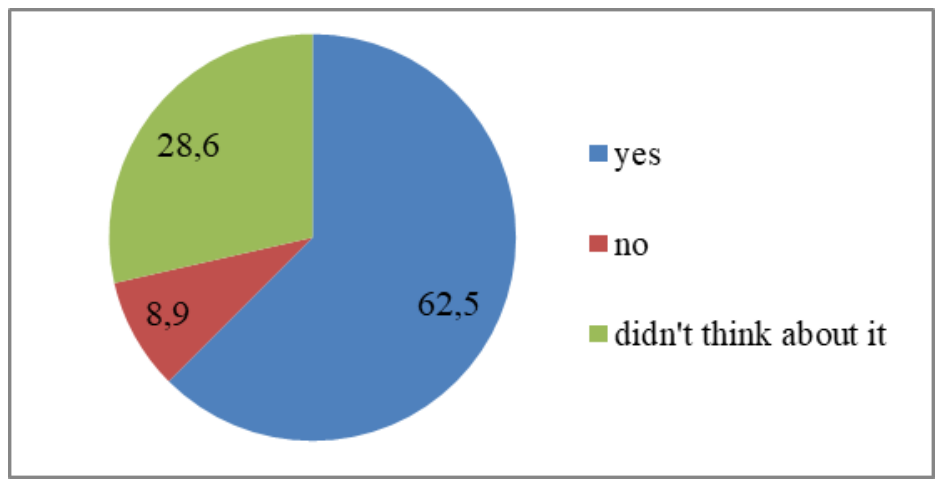

Fig. 1. Results of the survey «Would you be able to self-realize in the profession through management?»

Regarding the qualities that ensure the identification of organizational and managerial skills in the professional activities of the head of PEI, we want to note that the opponents were presented as follows: intellectual, business, specially professional, emotional, 
volitional, moral, and aesthetic, qualities that characterize the attitude to life and more. Thus, we found that 47 people $(83,9 \%)$ chose intellectual qualities; 39 people $(69,6 \%)-$ business, 38 people $(67,9 \%)$ - specially professional; 39 people $(69,6 \%)$ are emotional and volitional; 39 (69,9\%) - moral and ethical; 29 people (51,8 \%) - qualities that characterize the attitude to life and 1 person (1,8\%) chose other (fig. 2 ).

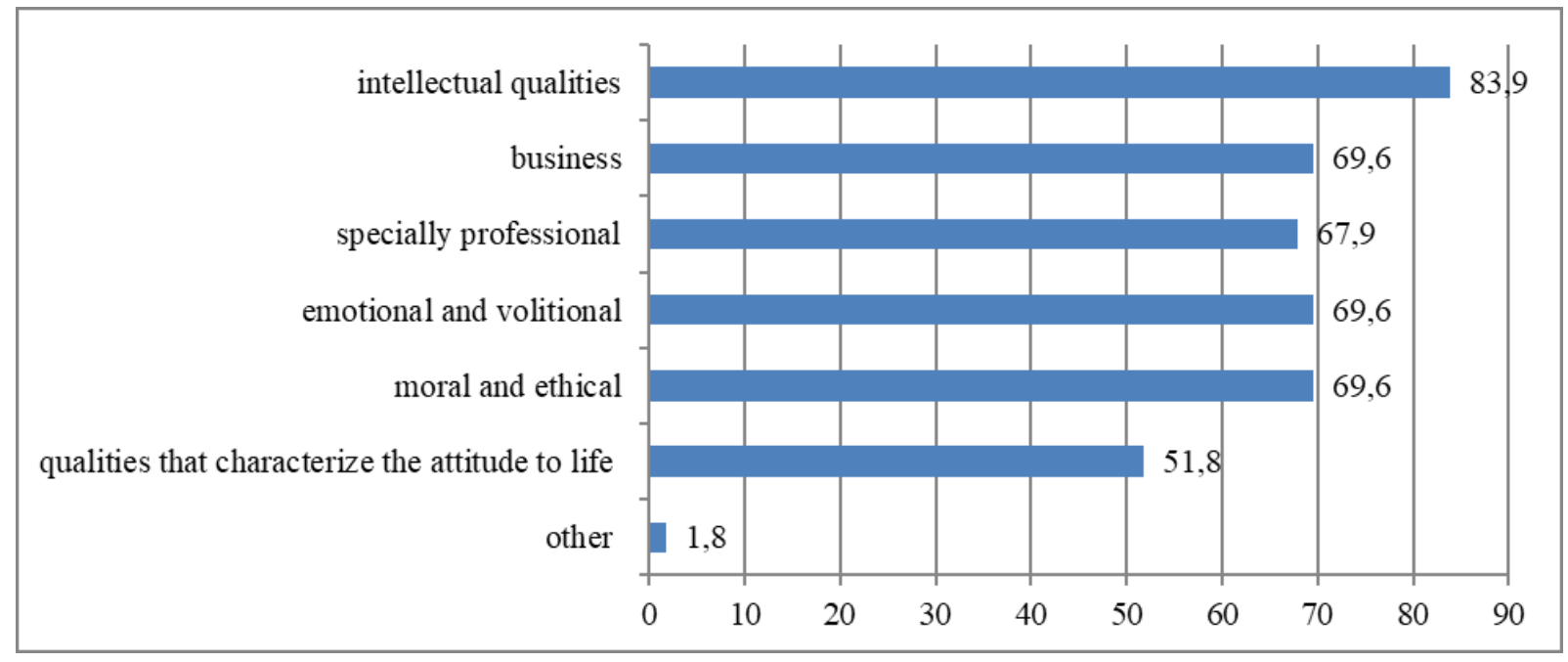

Fig. 2. The results of the survey «Choose the qualities that ensure the identification of organizational and managerial skills in the professional activities of the head of PEI»

In the course of carrying out the ascertaining stage of the experiment, it is found out that the summarized indicators of components of formation of leadership qualities of future leaders of PEI at the ascertaining stage of experiment make 20,54\% of high level, $55,7 \%$ of sufficient and $23,8 \%$ of initial levels that defines necessity of development and introduction of pedagogical conditions of their formation in the educational process of higher education institution. The results of the observational experiment prove that the future leaders of PEI have an insufficient level of leadership qualities. The current leaders of PEI show a higher level of development in all indicators of leadership development than students. The conducted analysis allows asserting about the necessity of definition and purposeful introduction of pedagogical conditions of formation of leadership qualities of the future heads of PEI in the educational process of establishments of higher education.

The implementation of the theoretical justification of the pedagogical conditions for the formation of leadership qualities of future leaders of PEI involves the disclosure of the essence of the concept of «pedagogical condition». Based on the analysis of scientific literature, the following basic provisions defining the essence of concept «pedagogical condition» are found out: «the forms, methods, material conditions, real situations which have objectively developed or subjectively created are necessary for the achievement of the concrete pedagogical purpose» (O. Infantry); «A set of objective possibilities of the content of education, methods, organizational forms and material possibilities of its implementation, which ensure the successful solution of the task» (O. Fedorova); a set of reasons, circumstances, any objects that affect the dynamics and final results of development, education, and training 
of the individual, can accelerate or inhibit these processes (N. Ippolitova, N. Sterkhova); a set of means, circumstances that contribute to the development or inhibition, effective implementation of the educational process (O. Brazhnych). Thus, based on the provisions of scientific works of O. Brazhnych, N. Ippolitova, O. Pekhota, N. Sterkhova, O. Fedorova, the basic concepts that define the content of the category «pedagogical conditions» are defined, namely: causes, circumstances, situations, factors; purpose, forms, methods, means, material conditions; efficiency of the educational process; results of development, education, training of the person; quality of preschool education.

In our study, the concept of «pedagogical conditions for the formation of leadership qualities of future leaders of preschool education» is understood as necessary to achieve specific educational goal forms, methods, tools, material conditions that combine a range of causes, circumstances, objects, situations, which objectively formed or subjectively created, and affect the dynamics and results of development, education, training of the individual, can accelerate or inhibit these processes, contribute to the effective implementation of the educational process or inhibit it, ensure the quality of preschool education.

Based on the provisions and results of the study conducted by B. Goloveshko, the pedagogical conditions for the formation of leadership qualities of future leaders of PEI are theoretically substantiated, in particular: motivational and value orientation of future leaders of PEI on successful management based on actualization of positive experience, creation of success situation; ensuring the mastery of the future leaders of PEI system of practically oriented, integrated knowledge about the phenomenon of leadership based on cognitive activation of students and their critical understanding of educational material; the use of personalityoriented technologies aimed at forming leadership skills in future leaders of PEI; formation of emotional and ethical competence of future leaders of PEI (M. Akhmetova, 2004).

We characterize the first pedagogical condition for the formation of leadership qualities of future leaders of PEI - motivational and value orientation of future leaders of PEI for successful management based on the actualization of positive experience, creating a situation of success.

According to the provisions formulated by A. Rean, the motive is considered as an internal motivation of the individual to activity, which is realized in the activity, communication, and behavior, associated with the satisfaction of a certain need. According to the scientist, motivation is an expression of personality orientation and combines stable motives in a certain hierarchy. M. Rokych notes that values are strong beliefs about appropriate ways of behaving and achieving the ultimate goal. The scientist defines terminal values, which are values-goals, which are manifested in the belief that the ultimate goal of an individual's existence is worth striving for it; instrumental values, ie values-tools that are based on the belief that the behavior and personal qualities of the individual corresponding to a particular situation. Based on the analysis of psychological and pedagogical literature, the following groups of motives are distinguished by the content of activities: social, cognitive, professional, material, and procedural. In the context of the study of the motivational and value orientation of future leaders of PEI on successful professional activity, we focus on the professional motives for the formation of their leadership qualities. B. Goloveshko understands professional motivation as a system of stable motives that motivate a person to 
master the knowledge, skills, and abilities of future managers, the formation of professional competence (M. Akhmetova, 2004).

Exploring professional motivation, H. Heckhausen identifies direct and indirect interests. The direct ones include specific professional interests that are manifested in the interest in the process and result of work, its objects, products, services; general professional interests, which include interest in the profession and its attractive features; romantic interest based on interest in the uniqueness of the profession; situational interest aimed at understanding the atypical properties of the profession (M. Akhmetova, 2004 and M. Didenko, 2013). Indirect interests related to the social and organizational characteristics of the profession combine cognitive interest, which is manifested in the desire to acquire new knowledge; prestigious interest in the pursuit of career growth and public recognition; interest in spiritual enrichment and intellectual development; uncertain interest, which is manifested in emotional satisfaction with the profession (M. Akhmetova, 2004 and M. Didenko, 2013).

$H$. Heckhausen considers the awareness of usefulness, the need of the individual in a particular field of activity as a motive of duty, combining several components, such as professional responsibility for their responsibilities and requirements of the profession, innovation, desire for self-realization, and self-improvement in the profession, altruistic aspirations (M. Akhmetova, 2004 and M. Didenko, 2013).

B. Goloveshko notes the relationship between cognitive and professional motives. The desire to succeed in professional activities leads to the emergence of an internal motive to acquire knowledge. Activation of cognitive motives contributes to the increase of professional motives, the formation of confidence of future leaders in their abilities, has a positive effect on their emotional attitude to future professional activities. According to the scientist, the combination of professional competence and leadership qualities are integral components of the management of the future head of PEI (B. Goloveshko, 2017). Important components of motivation of future leaders of PEI to successful professional activity are aspiration to constant personal and professional development, the realization of professional abilities, recognition of professionalism by other experts; focus on career development (B. Goloveshko, 2017).

The second pedagogical condition for the formation of leadership qualities of future leaders of PEI is to ensure the mastery of a system of practically oriented, integrated knowledge about the phenomenon of leadership based on cognitive activation of students and their critical understanding of educational material. The implementation of this pedagogical condition involves the definition of the theoretical foundations of the study of the phenomenon of leadership by future leaders of PEI. In the process of studying the material on leadership, it is advisable to use interactive forms and methods of learning, in particular: «brainstorming», thematic discussion, training, role play, and more.

The third pedagogical condition for the formation of leadership qualities of future leaders of PEI is the use of personality-oriented technologies aimed at the formation of future leaders of PEI leadership skills. The formation of individual-personal and sociopsychological qualities of future leaders of PEI is based on the following leadership skills: effective communication, time management, decision-making, managerial influence, team building, coaching, conflict management (M. Akhmetova, 2004). Implementation of effective 
communication is the basic professional competence of the head of PEI, which provides communication and feedback with the subjects of the educational process, the exchange of information vertically and horizontally, clear and logical presentation of their opinions and opinions orally and in writing; ability to formulate and justify their own position, informing employees about the tasks and expected results of activities; consulting and informing the public, readiness for public speeches, partnership with colleagues and heads of other institutions and organizations, the ability to listen, accept the ideas and positions of others, to find a compromise solution; discussion of different positions, views, and points of view; negotiation, ability (M. Akhmetova, 2004 and T. Batalova, 2004). The formation of effective communication skills contributes to the successful performance of the duties of the head of the PEI, the functions of the leader in terms of integration, purposefulness, and effective achievement of the goals of the PEI staff.

The specifics of the activity of the head of PEI presupposes the formation of time management skills, goal setting, and effective management of one's own time and the time of subordinates. L. Kucher notes that «the readiness of the manager to work effectively is determined by the practice of his daily activities, and the rational use of working time is crucial for the formation of leadership style. Clear establishment of planning periods contributes to a more accurate assessment of the situation as a whole, facilitates the selection of the main, increases the level of performance and helps the manager to make the right decision on how best to use working time» (T. Vezhevich, 2001).

Relevant for the formation of the above skills are defined by N. Alyushina provisions on individual or role-time management of leaders, such as awareness of their personal goals, their consistency with the overall goals of the organization; ability to plan own time based on fixing of the planned tasks, terms, resources; ability to set-top priorities; delegation of tasks to subordinates, the ability to rationally and efficiently use their time; ability to selfanalysis, self-development and creative activity, desire to improve own skills and abilities, to perform work as quickly and efficiently as possible; skills of «energy self-management», the ability to maintain a balance between work and rest, to make optimal use of self-motivation methods; ability to self-control, overcoming obstacles and solving unpredictable problems (I. Adizes, 2009).

Performing the function of a leader in targeting the activities of PEI staff involves the formation of his decision-making skills, which ensures the successful and effective performance of duties by PEI employees, creating a safe, comfortable, developmental, inclusive educational environment of PEI.

Implementation of managerial influence involves the purpose of the pedagogical staff of PEI to achieve certain educational goals, the formation of the ability to mobilize the efforts of each employee and the team as a whole to ensure the quality of preschool education, combining quality goal setting, quality of the educational process, quality of educational result quality of psychological and pedagogical conditions, quality of management of preschool education institution (S. Boyko, 2008).

The formation of coaching skills ensures the high-quality and effective performance of labor functions by the head of PEI, contributes to the achievement of specific personal and professional educational goals. Foreign researchers M. Atkinson, J. Whitmore, R. Chois note 
that «coaching reveals a person's potential and helps him to achieve maximum efficiency» (Z. Gaponyuk, 2008), «helps to acquire the skills needed to realize creative abilities, increase personal effectiveness in the process of achieving the goal, to learn individual values, teaches to support employees in unleashing their potential» (M. Akhmetova, 2004).

Execution of labor functions of the head of PEI presupposes the formation of conflict management skills, which combines the following components: understanding the essence of the conflict; objective attitude to all parties to the conflict, manage their own and their emotions; provide an opportunity to express their arguments; understand and take into account the interests and motives of the parties (B. Goloveshko, 2017); to search for different options for reconciling the interests of the parties; provide flexibility, positivity, show emotional stability, have the ability to solve problems of each party, find compromises, offer different ways of agreement between the parties on a positive solution; be able to direct the communication of the parties to the conflict to determine the essence of the problems, ways to solve them, express constructive suggestions, their analysis, and discussion, coordination.

To influence the individual-personal and socio-psychological qualities of the individual, allowing the manager of administrative activities to understand and manage their own and others' emotions.

The fourth pedagogical condition for the formation of leadership qualities of future leaders of PEI is the formation of their emotional and ethical competence, which is manifested in the ability to realize personal feelings and emotions, to manage their own emotional states; ability to conscious, constructive and environmental interaction with participants in the educational process and local communities; ability to understand and appreciate the interdependence of the subjects of the educational process (K. Voronina, 2009).

The formation of emotional and ethical competence of future leaders of PEI involves mastering knowledge about the types and intensity of emotions, the reasons for their occurrence; modern forms, methods, technologies and teaching aids that promote the development of selfattention, self-regulation, emotion management and understanding; methods of dialogue and polylogue, conscious and empathic listening, non-violent communication; developing skills to understand the diversity and uniqueness of different cultures in society, differences between people, methods of prevention, overcoming and transformation of conflicts; awareness and constructive response to the manifestations of emotions without condemnation; mastering the ways of self-preservation of mental health, awareness and management of one's own emotions; constructively respond to stress, conflict situations, promote understanding of the subjects of the educational process; apply the practices of concentration, conscious emotional response, choose and implement appropriate emotional response depending on the communicative situation; organize a dialogue and polylogue with participants in the educational process and community representatives, respect their rights and social values; apply in discussions of educational, social and life problems methods of conscious and empathic listening and nonviolent communication; apply in the educational process the practice of critical thinking, awareness and understanding of other people's emotions; to take into account in communication cultural and personal differences of interlocutors, their advantages and limitations, to show understanding and empathy, to promote reconciliation (K. Voronina, 2009). 
Thus, as a result of scientific research, the pedagogical conditions for the formation of leadership qualities of future heads of preschool education institutions have been identified and substantiated, which will contribute to the formation of their professional competence and require experimental verification of their effectiveness in the educational process. During the formative stage of the experimental study in the process of training future leaders of PEI in higher education institutions, four pedagogical conditions were implemented to positively influence the level of formation of motivational-value, integrativeactivity, directional-activity, and emotional-reflexive components of leadership qualities. . The implementation of pedagogical conditions was carried out in the form of problem and review lectures, seminars-discussions and practical training sessions within ten separate content modules, which were defined following the pedagogical goals.

Thus, the formative stage of the experiment involved the introduction of pedagogical conditions for the formation of leadership qualities of future leaders of PEI. To track the dynamics of the formation of leadership qualities of future leaders of PEI, a control phase of the experiment was conducted, which involved re-diagnosing certain components and tracking the dynamics of change.

After the formative stage of the experiment, the positive dynamics of all components of the levels of formation of leadership qualities of future leaders of PEI are traced. At a high level of growth of indicators of formation of leadership qualities of future leaders of PEI makes $11,66 \%$ (from $20,54 \%$ to $32,2 \%$ ). At a sufficient level, there is an increase in indicators by $7,75 \%$ (from $55,7 \%$ to $63,45 \%$ ); at the initial level, there was a decrease in indicators by $0,5 \%$ (from $23,8 \%$ to $23,3 \%$ ). The overall growth rate of leadership qualities of future leaders of PEI is $18,91 \%$, which confirms the effectiveness of the introduction of pedagogical conditions for the formation of leadership qualities in future leaders of preschool education.

The results of the pedagogical experiment confirm the expediency of introducing the developed pedagogical conditions for the formation of leadership qualities in the process of professional training of future heads of preschool education institutions in higher education institutions.

\section{DISCUSSIONS}

Based on the analysis of the scientific literature, it was found that scientists pay special attention to the study of leadership problems in management (J. Antonakis, L. Bolman, R. Birnbaum, B. Goloveshko, T. Deal, D. Goleman, J. Ilias, J. Kotter, K. Levin, S. Nestulya, X. Owen, R. Presiosi, R. Stenberg, O. Yatsenko, etc.), psychology (T. Bendas, K. Voronina, T. Gura, V. Zazykin, L. Karamushka, B. Parigin, L. Pochebut, I. Meizhis, N. Radina, S. Taylor, etc.), pedagogy (D. Alfimov, I. Drach, S. Kalashnikov, V. Karmanenko, V. Moroz, O Romanovsky, R. Sopivnyk, V. Yahodnikova, etc.). The pedagogical intelligence of V. Lokshin, T. Makhina, S. Novikova, O. Romanovsky, V. Salyakhov, N. Yurtaeva, O. Yatsenko is devoted to the topic of development of leadership qualities in future managers, and M. Hasanova, B. Goloveshka, I. Drach, S. Kalashnikova, G. Tymoshko.

Determination of pedagogical conditions of formation of leadership qualities of future leaders of PEI is carried out by us based on results of scientific researches on the essence of pedagogical conditions of professional training in $\mathrm{ZVO}$, the educational process of the 
educational institution (A. Aleksyuk, A. Ayurzanain, O. Brazhnych, Yu. G. Golubova, R. Gurova, A. Zubko, N. Ippolitova, V. Manko, P. Podkasisty, O. Pekhota, N. Stadnyk, N. Sterkhova, O. Fedorova, B. Chizhevsky, etc.).

Thus, despite the significant development of the issue of the formation of leadership qualities of specialists, the problem of the formation of leadership qualities in future heads of preschool education remains insufficiently studied.

\section{CONCLUSIONS}

The research of the problem was carried out in three stages: at the first stage the theoretical analysis of the existing methodological approaches in philosophical, psychological, and pedagogical scientific literature, dissertations on the problem, as well as the theory and methods of pedagogical research was carried out; the problem, the purpose and methods of research are outlined, the plan of experimental research is made. At the second stage, the pedagogical conditions for the formation of leadership qualities of future leaders of preschool education institutions are determined and substantiated, which will contribute to the formation of their professional competence and require experimental testing of their effectiveness in the educational process of higher education institutions; experimental research work was carried out, the conclusions received during experimental work were analyzed, checked and specified. At the third stage the experimental work was completed, theoretical and practical conclusions were specified, the received results of the research were general and systematized.

In our study, we proceed from the fact that the definition of criteria and indicators, levels of leadership qualities of future leaders of preschool education combines the following structural components: motivational and value, combining a set of motives and values that determine the success and effectiveness of the leader; integrative-activity, based on which a set of organizational and communicative abilities that provide the ability of the head of the preschool education institution to integrate the teamwork of the staff of preschool education institutions; directional activity, which combines a set of decision-making skills and defining goals that ensure the purpose of the team; emotional-reflexive, which is determined by a set of abilities to recognize and manage their own emotions and the emotions of others, ensuring the ability of the head of the preschool institution to express itself as a standard.

As part of the implementation of the first pedagogical condition, the issue of development and formation of a set of professional motives in students, which are the basis for both educational activities and future professional success. Thus, for the implementation of the first pedagogical condition for the formation of leadership qualities was developed methodological support of practical classes with meaningful exercises to gain students a positive emotional experience of achieving artificially activated goals, increase their selfesteem and personal motivation to achieve, value orientations. As part of the implementation of the second pedagogical condition, the question of effective assimilation of knowledge by students, which should serve as a basis for the formation of their own concept of self-leader and a basis for a theoretical understanding of the principles of management. To implement the third pedagogical condition, review and problem lectures, seminars-discussions, and 
practical training sessions were held, the content of which was determined by the need to form certain applied leadership skills. The content of tasks is summarized to ensure that future leaders of the PEI perform the integrative function of a leader (exercises for applying skills in team building, conflict management, effective communication) and purposeful function of a leader (exercises for applying skills in coaching, decision making, time management). influence skills). The workshop organized in this way was aimed at forming integrative-activity and direction-activity components of leadership qualities. By performing the exercises, students had the opportunity to develop organizational and communication skills and the ability to set goals, plan, and make decisions accordingly. The next stage in the formation of team-building skills was to conduct practical classes, training. The next step was to consolidate the acquired knowledge and develop skills in effective communication through seminars-discussions on the topic: «Styles of behavior and communication in management». Thus, the content of tasks was summarized to ensure that future leaders of the PEI perform the integrative function of a leader (exercises for the application of skills in team building, conflict management, effective communication) and purposeful function of the leader (exercises for applying skills in coaching, decision making, time). -management, skills of influence). The workshop organized in this way was aimed at forming integrative-activity and direction-activity components of leadership qualities. By performing the exercises, students had the opportunity to develop organizational and communication skills and the ability to set goals, plan, and make decisions accordingly. During the implementation of the fourth pedagogical condition, we took into account the results of research that indicate the possibility of a positive experience in the development of emotional intelligence (B. Goloveshko, 2017). Thus, to implement the fourth pedagogical condition, practical exercises were developed that allowed students to analyze their own and others' emotions, identify various emotions, form knowledge about the manifestation of emotions through observation, manage their own and others' emotions. The implementation of pedagogical conditions took place in the following organizational forms: within the framework of achieving a certain pedagogical goal, problematic and review lectures were held, consolidation of acquired knowledge and skills development through thematic discussions, final skills formation took place during practical classes, pieces of training. Therefore, after the formative stage of the experiment, there is a positive dynamics of indicators of the formation of leadership qualities according to the components and criteria defined in the study.

\section{REFERENCES}

The proposed materials of the article are of practical value for heads of preschool education institutions, educatorsmethodologists, and future teachers of preschool education.

Adizes, I. (2009). Management Styles - Effective and Ineffective. Moscow: Alpina Business Books, 199 p.

Alfimov, D. V. (2010). The Content of the Phenomenon of «Leadership Qualities of the Individual. Pedagogy of Creative Personality Formation in Higher and General Education Schools. Zaporizhia, 11 (64), 44-51.

Akhmetova, M. N. (2004). Project Culture of the Future Teacher. School Technologies, 4, 210-218.

Batalova, T. V. (2004). Personal Determinants of the Process of Professional Development of Managers in Higher Education. Abstract PhD Thesis. Moscow, 20 p. 
Blanchard, K. (2008). Leadership: to the Pinnacle of Success. Saint Petersburg: Peter, 2008. 368 p.

Boyko, S. S. (2008). Curriculum of the Discipline «Methodology, Methods and Tools of Administrative Management» (for Masters). Kyiv: MAUP, 2008. Retrieved from: https://cutt.ly/XhcIWXo.

Vezhevich, T. E. (2001). Pedagogical Conditions of Development of Leadership Qualities of Students. Abstract PhD Thesis. Ulan-Ude, $20 \mathrm{p}$.

Volynets, Yu. O. \& Stadnik, N. V. (2019). Pedagogical Conditions of Formation of Leadership Qualities of the Future Teacher in the Conditions of European Integration. Professional Development of the Teacher in the Light of European Integration Processes. Hameln: InterGING, 66-84.

Voronina, K. O. (2009). Features of Studying the Level of Leadership Skills. Problems of General and Pedagogical Psychology: Collection. Science. etc. Institute of Psychology. G. S. Kostyuk Academy of Pedagogical Sciences of Ukraine. Kyiv, 11, 3. 99-107.

Gaponyuk, Z. G. (2008). Pedagogical Conditions for the Formation of Leadership Qualities in Students of Humanities Universities. Abstract PhD Thesis. Moscow, 24 p.

Goloveshko, B. R. (2017). Pedagogical Conditions of Formation of Leadership Qualities in Future Specialists in Administrative Management in Higher Educational Institutions. Abstract PhD Thesis. Kharkiv, 294 p.

Eliseev, O. P. (2003). Workshop on Personality Psychology. Saint Petersburg: Peter, 512 p.

Zeer, E. F. (2003). Psychology of Professions: a Textbook for University Students. Moscow: Academic Project; Ekaterinburg: Delovaya kniga, $336 \mathrm{p}$

Zorina, A. V. (2009). Pedagogical Conditions for the Formation of Leadership Qualities in University Students. Abstract PhD Thesis. Nizhny Novgorod, 25 p.

Ilyin, E. P. (2000). Psychology of Will. Saint Petersburg: Piter, 288 p.

Kalashnikova, S. A. (2010). Educational Paradigm of Professionalization of Management Based on Leadership. Kyiv: Kyiv. Univ. B. Grinchenko, 390 p.

Karpov, A. V. (2003). Psychology of Labor: Textbook. for Students. Higher Textbook Routine. Moscow: VLADOS-PRESS, $352 \mathrm{p}$.

Klishchevskaya, M. V. \& Solntseva G. N. (1999). Professionally Important Qualities as Necessary and Sufficient Conditions for Predicting the Success of Activities. Bulletin of Moscow University, 14(4), 61-64.

Lokshin, V. S. (2013). Formation of Leadership Qualities of Future Managers of Socio-Cultural Activities in the Context of the Process of Modernization of Higher Education. Spirituality of Personality: Methodology, Theory and Practice. Lugansk, 1(54), 109-120.

Lucin, D. V. (2006). A New Method for Measuring Emotional Intelligence: EmIn Questionnaire. Psychological Diagnostics, 4, 3-22.

Morgulets, O. B. (2012). Management in the Field of Services: Textbook. Kyiv: Center for Educational Literature, $384 \mathrm{p}$.

Morosanova, V. I. (1995). Individual Style of Self-Regulation in Arbitrary Human Activity. Psychological Journal, 4. 26-35.

Pilganchuk, A. \& Kuzmenko, V. (2012). Development of Leadership Skills in Future Psychologists. Humanities. Bulletin of Pereyaslav-Khmelnytsky State Pedagogical University named after G. Skovorody, 25, 412-415.

Pushkar, Z. M. \& Pushkar, B. T. (2017). Personnel Management: Textbook. Ternopil: Osadtsa Yu.V., 210 p.

Rozanova, V. A. (1999). Psychology of Management. Moscow, CJSC «Business School» Intel-Synthesis, 352 p.

Senin, I. G. (1991). Questionnaire of Terminal Values. Yaroslavl: NPC «Psychodiagnostics». Assistance Civil Initiative Foundation, $19 \mathrm{p}$.

Stadnik, V. V. \& Johna, M. A. (2003). Management: a Guide. Kyiv: Akademvydav, 464 p.

Fetiskin, N. P., Kozlov, V. V. \& Manuilov, G. M. (2002). Socio-Psychological Diagnostics of Personality Development and Small Groups. Moscow: Publishing House of the Institute of Psychotherapy, $490 \mathrm{p}$. 
Romanovsky, O. G., Ponomarev O. S., Ignatiuk O. A. (2011). Formation of Psychological Readiness of Future Specialists for Professional Activity. Kharkiv: Publisher Savchuk O. O.; NTU «KhPI», 336 p.

Shadrikov, V. D. (1982). Problems of System Genesis of Professional Activity. Moscow: Nauka Publishing House, 185 p.

Yakushko N. O. (2018). Theoretical Principles of Leadership Research in Domestic and Foreign Management Science. Governance, 1 (61), 25-29. Retrieved from: http://pa.stateandregions.zp.ua/archive/1_2018/7.pdf.

Hernez-Broome, G. \& Hughes, R. L. (2004). Leadership Development: Past, Present, and Future. Human Resource Planning, 27(1), 24-32.

Krasikova, D. V., Green, S. G. \& LeBreton, J. M. (2013). Destructive Leadership a Theoretical Review, Integration, and Future Research Aagenda. Journal of Management, 39(5), 1308-1338.

Lawson, K. (2009). Leadership Development Basics (Training Basics). ASTD Press, 128 p.

Selznick, P. (2010). Leadership in Administration: A Sociological Interpretation. Auckland: University of California Press, $162 \mathrm{p}$

Stale, E., Aasland, M. \& Skogstad, A. (2007). Destructive Leadership Behaviour: A Definition and Conceptual Model. The Leadership Quarterly, 18, 207-216. 